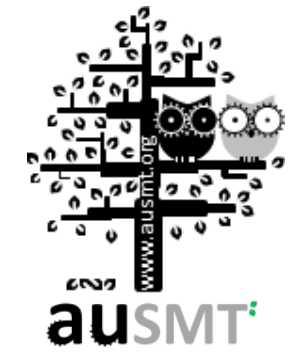

\title{
Using the Zero-Resistance Spark Circuit on the Wire Cut Electric Discharge Machine to Realize Energy Savings
}

\author{
Shao-Hsien Chen ${ }^{1 *}$, and Chen-Peng Wang ${ }^{2}$ \\ ${ }^{1}$ Department of Mechanical Engineering, National Chin-Yi University of Technology, Taiwan \\ ${ }^{2}$ Department of R\&D, Ching Hung Machinery \& Electric Industrial CO., LTD, Taiwan \\ (Received 19 November 2013; Accepted 7 February 2014; Published on line 1 September 2014) \\ *Email: e6036@ncut.edu.tw \\ DOI: 10.5875 /ausmt.v4i3.369
}

\begin{abstract}
There is an increasing emphasis on the development green manufacturing technologies. To improve processing and energy efficiency of modern Wire Cut Electric Discharge Machines (WEDM), many studies have focused on the design of the device's discharge circuit. Currently, most such circuits use a resistor to impose current-limitations. When current flows through this resistor, considerable electrical energy converted into heat. The generated heat increases the temperature in the discharge circuit, which negatively impacts processing and energy efficiency, even though the temperature rise could be controlled by arranging cooling devices around the discharge circuit. This study seeks to produce an improved discharge circuit for use in WEDMs. We use DC-DC and electronic voltage regulation technology to convert the energy originally dissipated in the resistor directly into the energy for use in machining. The Zero-Resistance Spark Circuit is the critical design to realize the energy saving effect. Experimental results indicate energy savings of 10 to $15 \%$.
\end{abstract}

Keywords: Wire Cut Electric Discharge Machine; Zero-Resistance Spark Circuit; Machine tools

\section{Introduction}

The Wire Cut Electric Discharge Machine (WEDM) is one of key tools used for precision mold processing, but operating such devices tend to use considerable amounts of energy. Current design trends are towards energy efficiency and energy could potentially be conserved in WEDM operation through component or process redesign. Lee found that green machine tools possess relative low energy efficiency [1]. For example, only $25 \%$ of the electrical energy consumed by the machine tool was practically used for machining, and more than one-half of the electrical energy consumed by the machine tool was wasted on circuit transmission loss or maintaining standby mode. Also, the renewable materials are used to decrease the size and weight of the machine tools, so the used materials can be recycled and regenerated for green manufacturing.

Modern machine tools are designed based on considerations of energy efficiency and green manufacturing, DMG [2] has proposed to reduce non-productive energy use by at least $75 \%$ through the use of a mechanism which shifts the machine tools into a power-down mode when not in use. This reduces energy use by peripheral devices, such as high efficiency motors operating at optimum speed to match torque. 


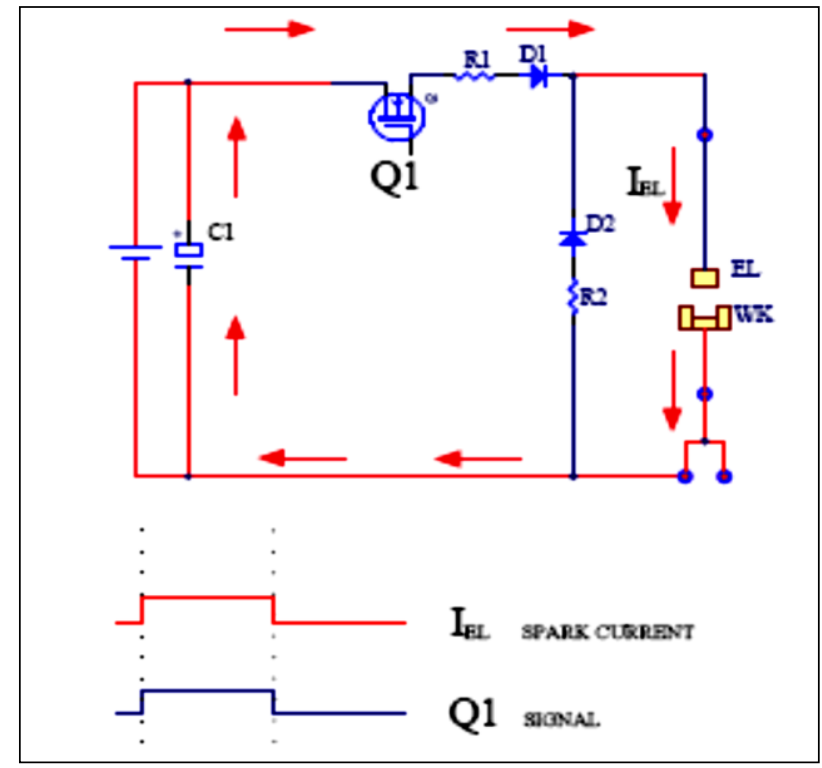

Figure 1. Discharge equivalent circuit of resistance spark circuit with Q1 on.

WEDMs are commonly used in mold processing for parts requiring straightness and roundness, such as the punch and guide post of stamping dies. Plastic molds can provide finished products with a surface gloss through using an intensive WEDM loop, and taper machining with WEDM can facilitate plastic mold release. WEDMs also haves advantages in terms of part processing, and provides good play space for small parts and parts without burrs, such those used in wrist watches or medical equipment.

This study proposes a mechanism for recycling energy from the WEDM discharge circuit. By redesigning the WEDM driving circuit, we convert the energy originally dissipated in the WEDM driving circuit's resistor to reusable energy for WEDM in the machining process [3-5]. This is implemented primarily by applying multiple transistors to control the discharge states, so as to recycle the dissipated energy for further use and to enhance the electrical efficiently of the WEDM [6-8].

\section{Shao-Hsien Chen received the B.S. degree in Mechanical Engineering at the National Chin-Yi University of Technology, Taichung, Taiwan, in 1992, and the M.S. and Ph.D. degrees in Mechanical Engineering at the National Chung Cheng University, Chia-Yi, Taiwan, in 2000 and 2006, respectively. He joined the faculty of the Department of Mechanical Engineering ,National Chin- $Y_{i}$ University of Technology(NCUT), Taichung, Taiwan, in August 2009. He is currently an Assistant Professor. His research interests include High Speed Machining, Machine Tool Design and Analysis, Machine Tool Precision Assembly. Work experience to work in the company of AWEA, Chmer, PMC and LEADWELL of 16 years, mainly working for precision mechanical design - measurement and processing application that the position of the engineer to manager.}

Chen-Peng Wang received the M.S. degree in Mechanical Engineering at the National Chin-Yi University of Technology ,Taichung, Taiwan, in 2013, He joined the faculty of Department of R\&D, Ching Hung Machinery \& Electric Industrial CO., LTD, Taichung, Taiwan He is currently R\&D leader, His research interests include WEDM application and Machine Tool Design and Analysis.

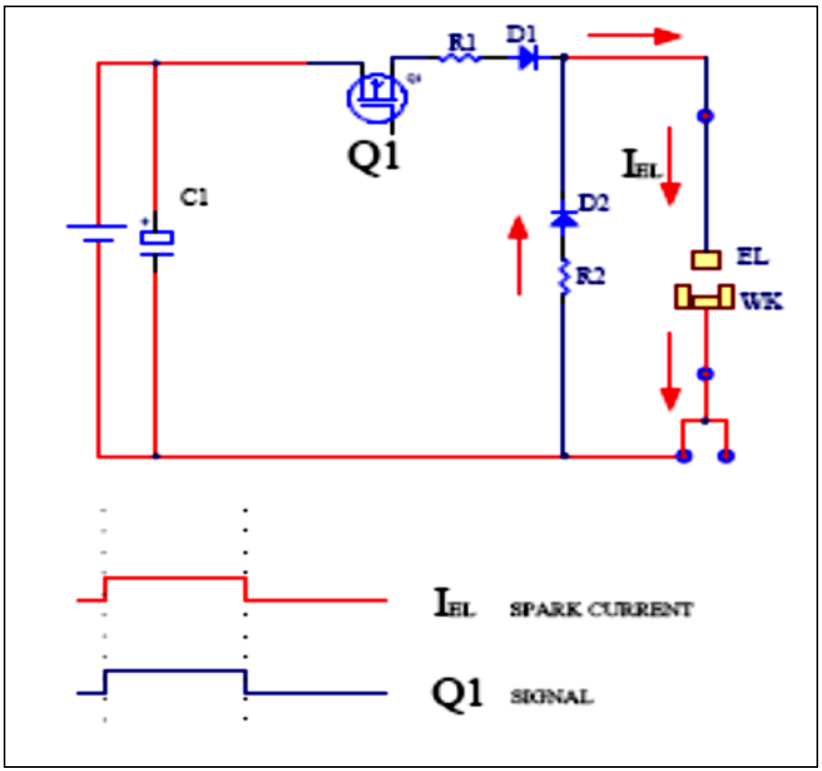

Figure 2. Discharge equivalent circuit of resistance spark circuit with Q1 off.

\section{WEDM discharge circuit}

\section{WEDM discharge principle}

In general, there are three main kinds of discharge loops for electrical discharge machining (EDM). The first discharge loop (capacitor-discharge) uses the capacitor for discharge. When the discharge function is turned on, the capacitor releases its stored energy for processing. The second discharge loop (transistor-discharge) uses the switch function of the transistor to directly control the DC power, allowing the power output to the electrode and workpiece. The third discharge loop is the transistor-controlled capacitor-discharge loop, which combines the advantages of the first and second kinds of loops and is commonly used in current WEDM. This loop allows the capacitor to be charged and the electrical energy is therefore stored in the capacitor. The transistor then toggles to control the charging state. In this loop, the capacitor can store charged energy and then toggle it on and off quickly, thus transmitting the energy stored in the capacitor to the WEDM with remarkably high voltage and current conditions at discharge since the transistor can quickly toggle on and off to achieve a short pulse and stable discharge control. This results in an effective energy supply for electrical discharge machining.

Figure 1 shows the discharge process in a resistance spark circuit [4]. When MOSFET Q1 is turned on, the current is conducted to the end of electrode $\mathrm{EL}$ through capacitor $\mathrm{C} 1$, and the discharge current acts on the workpiece WK. Figure 2 shows that Q1 is shut off to stop the discharge process, thus accelerating the 
discharge current flow through the resistor R2.

Power consumption (W) during electrical discharge machining can be calculated as follows:

$$
\begin{aligned}
& W=V \times I \times T \times F_{q} . \\
& V: \text { discharge voltage }(\text { Volt }), \\
& I: \text { discharge current }(\mathrm{Amp}), \\
& T: \text { current duration }(\mathrm{Sec}), \\
& \mathrm{Fq}: \text { discharge frequency }(\mathrm{KHz}) .
\end{aligned}
$$

Energy (E) required for removing each unit volume of material can be expressed as,

$$
\begin{aligned}
& E=\frac{W}{G \times H \times F_{d}} . \\
& G: \text { Machining width }(\mathrm{mm}), \\
& H: \text { workpiece thickness }(\mathrm{mm}), \\
& F d: \text { bed } \xi \text { feed rate }(\mathrm{mm} \mathrm{sec}) .
\end{aligned}
$$

where the denominator is the metal removal rate., which refers to the processing capacity of the material being cut during machining using the WEDM.

\section{Zero-Resistance Spark Circuit}

One major contribution of this work is the implementation of a zero-resistance spark circuit, which is defined as a discharge loop circuit which does not require a resistor. As shown in Figure 3 , through the presented energy regeneration loop circuit, the energy of the counter Electric Motive Force (abbreviated counter EMF, i.e., the voltage that pushes against the current which induces it) which originally crosses the discharge loop resistor during discharge (e.g., the voltage drop across R2 in Figure 2) can be recycled for more efficient discharge, thus minimizing unwanted heat generation.
When the zero-resistance spark circuit is used for machining, it reuses the energy which would otherwise have been dissipated. Based on the principle of energy conversion, the zero-resistance spark circuit converts the dissipated energy originally produced in the discharge loop's resistor to discharge energy to improve the electrical efficiency of machining. This also prevents cooling problems resulting from heat produced by the resistor in the original discharge loop.

In this study, the external main power supply AC220V is provided to the controller and transformer of the WEDM, and the controller is mainly responsible for overall control. This block diagram (Figure 3) illustrates the part of discharge control. The controller of the discharge circuit controls the discharge timing sequence, which mainly processes conditions such as ON TIME and OFF TIME. The transformer converts the main AC power to $D C$ power which is then converted into the required discharge voltage with a DC value through the 'discharge power function (Figure 3). The resulting DC voltage mainly provides the discharge power and is used as the source of discharge energy. This energy is first stored in the capacitor $\mathrm{C} 1$, waiting for the discharge switch which is controlled by the discharge control, to be switched on or off.

During machining, the controller controls the discharge control function according to the machining parameters set by the operator. The discharge condition can be determined by setting the discharge duration ON and OFF in a given machining process. The controller turns the discharge switch ON when it confirms that the environment has reached the discharge condition. The ON/OFF switching produces a counter EMF and results in the quick opening and closing of the discharge switch.

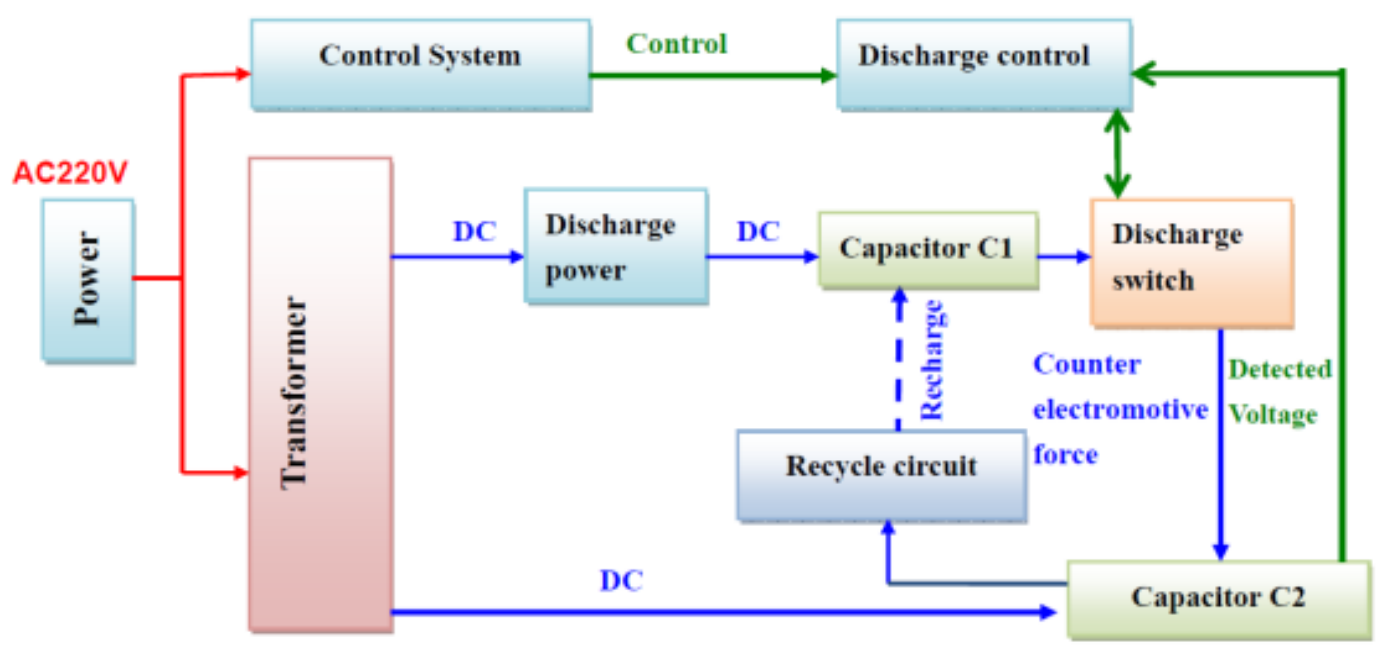

Figure 3. Working block diagram of zero-resistance spark circuit. 


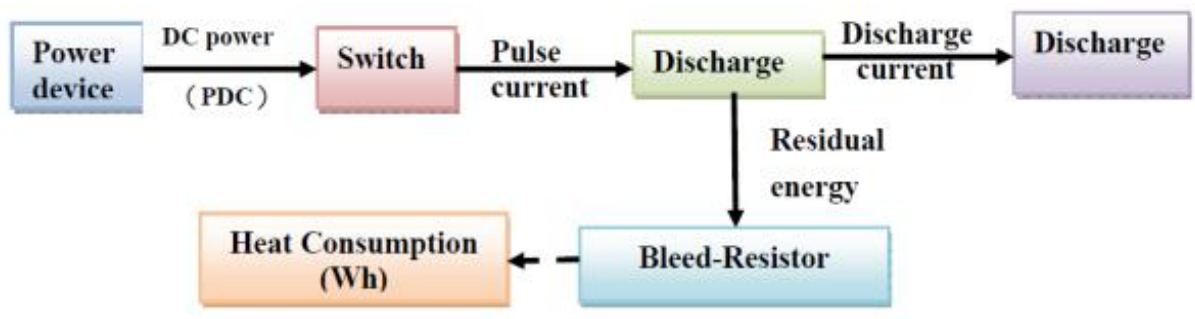

Figure 4. Discharge power block diagram.

For a conventional circuit, this counter EMF is discharged by resistance. However, in a zero-resistance spark circuit, this energy is directly stored in the C2 capacitor, and then boosted by the recycle circuit. When the voltage in the recycle circuit exceeds that of the $\mathrm{C} 1$ capacitor, it automatically flows to $\mathrm{C} 1$ as the energy to be used for the next discharge. This is the basic operation principle of the zero-resistance spark circuit.

Figure 4 illustrates the circuit board for the zero-resistance spark circuit, mounted on the WEDM for discharge testing. When the power supply device generates DC power, the switch turns ON and OFF. When the switch is turned on, it produces discharge power through the discharge device. However, when discharge is stopped, it needs to transfer the residual energy to the bleed-resistor as heat for dissipation. Therefore, the discharge power can be described as follows:

$$
\begin{aligned}
& W=W d-W h \\
& W: \text { discharge power, } \\
& W d: D C \text { power, Wh: Heat Consumption. }
\end{aligned}
$$

\section{Experimental planning and equipment}

This study analyzes and tests a resistance spark circuit and a zero-resistance spark circuit. The first stage sets the machining parameters and analyzes the impact of different discharge circuits on machining energy, so as to verify the energy savings by the zero-resistance spark circuit on discharge machining; the second stage sets the machining parameters and analyzes the impact of different discharge circuits on machining speed; the third stage changes the machining parameters and analyzes the impact of different discharge circuits on machining speed $[9,10]$.

A WEDM produced by CHMER Group is used as the experimental equipment. The main device is composed of a servo control with five axes $(X \sim Z)$, a feed device driven by copper wire, machining power supply systems, a CNC controller and a machining liquid supply device. The device is shown in Figure 5, and the mechanical specifications are listed in Table 1 [5].

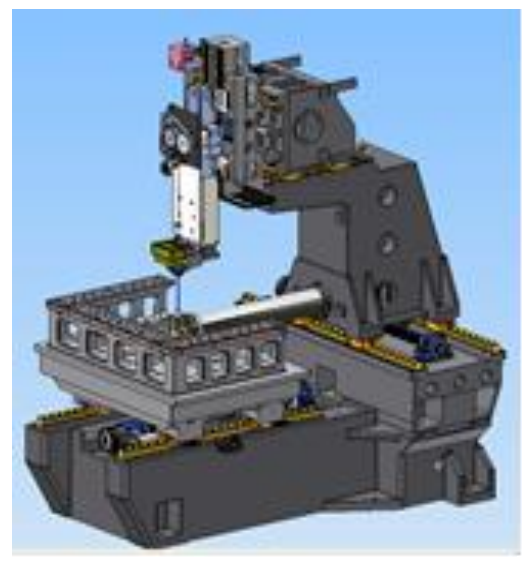

\begin{tabular}{|c|c|c|}
\hline Model & Unit & G32S Submerse \\
\hline $\mathrm{X}, \mathrm{Y}$ route & $\mathrm{mm}$ & $360 \times 250$ \\
\hline $\mathrm{U}, \mathrm{V}, \mathrm{Z}$ route & $\mathrm{mm}$ & $60 \times 60 \times 220$ \\
\hline Max workpiece (WxDxH) & $\mathrm{mm}$ & $725 \times 560 \times 215$ \\
\hline Weight of max workpiece & $\mathrm{kg}$ & 300 \\
\hline Motor System & axis & AC servo motor \\
\hline Wire diameter (standard) & $\mathrm{mm}$ & $\phi 0.15^{\sim} \phi 0.3(\phi 0.25)$ \\
\hline Wire tension & gf & $300 \sim 2500$ \\
\hline $\begin{array}{l}\text { N.W(including power } \\
\text { and water system) }\end{array}$ & $\mathrm{kg}$ & 2375 \\
\hline Machining speed & $\mathrm{mm}^{2} / \mathrm{min}$ & $150 \sim 200$ \\
\hline Surface granularity & $\mathrm{Ra}$ & $\begin{array}{c}0.5^{\sim} 0.6 \\
\text { (Three-pole processing) }\end{array}$ \\
\hline
\end{tabular}

Figure 5. WEDM Structure.

Table 1. Table of Specifications and Performance.

\section{Results and discussion}

\section{Impact of different circuits on machining power}

This study compares the machining power for the zero-resistance spark circuit and resistance spark circuit. Table 2 summarizes the fixed machining parameters. An electric power meter is used to observe the variation of external input power on machining. As seen in Figure 6, the measurements indicate that machining for less than 1 hour has no significant impact, but more significant differences emerge after 9 hours machining. This is primarily because of the reduced electrical efficiency of the the energy being dissipated in the resistor. Moreover, energy conversion and saving the dissipated energy in a predesigned capacitor though the recycle circuit can increase the machining energy between the workpiece and electrode and avoid unwanted heat generation in the discharge loop circuit. 
Table 2. Cutting Conditions.

\begin{tabular}{ccc}
\hline Parameter & Function & Value \\
\hline ON & On Time & 7 \\
OFF & Off Time & 8 \\
AN & Arc On Time & 5 \\
AFF & Arc Off Time & 9 \\
SV & Servo Voltage & 38 \\
FR & Feed-rate Override & 15 \\
WF & Wire Feed & 7 \\
WT & Wire Tension & 8 \\
WL & Water Flow & 6 \\
\hline
\end{tabular}

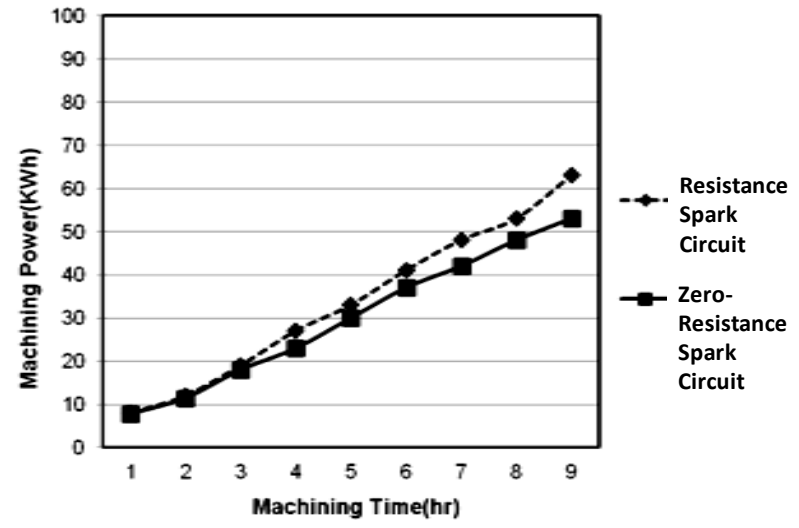

Figure 6. Comparison of power consumption of resistance and zero-resistance spark circuit.

Comparison of power consumption under identical speed conditions

WEDM cutting power consumption is primarily impacted by the inter-relation of parameters such as discharge voltage, discharge current, current duration, discharge frequency, material properties and cutting speed. Figure 7 shows the impact of the different circuits on power consumption given changes to cutting speed, as calculated using Equations (1) and (2). The zero-resistance spark circuit consumes less power at the same machining speed. The main reason is the discharge power generated very little heat for the zero-resistance spark circuit. Additionally, equation 3 shows power consumption is negatively correlated to cutting speed [11, 12].

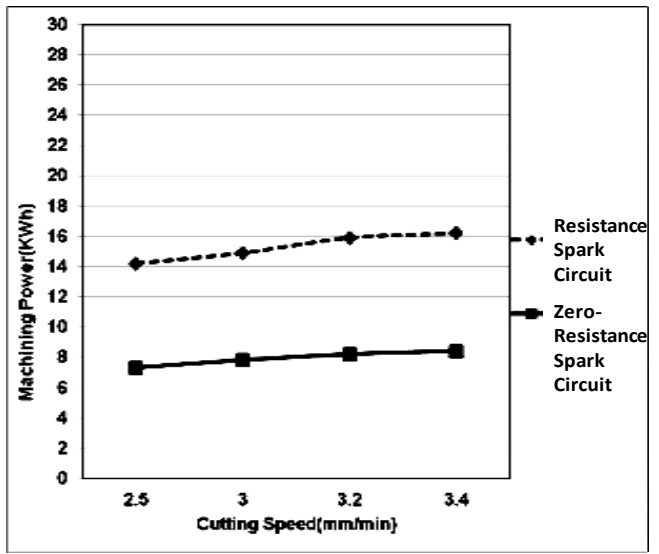

Figure 7. Impact of different machining speeds on power consumption.

\section{Conclusion}

This study applies the zero-resistance spark circuit to the WEDM to realize energy savings. By removing the resistor used in conventional discharge loop circuits, the counter EMF across the original resistor results in power dissipation and heat generation and can be used to charge a predesigned capacitor so as to recycle the dissipated energy. Removing the original resistance also eliminates the heat energy converted by the resistance through the generation electric energy. This recycling of energy contributes to overall energy savings $[13,14]$.

The key findings of this study are as follows:

1. Energy savings can be achieved by changing the original resistance spark circuit to the zero-resistance spark circuit with the discharge energy through a process of energy storage and boosting. Removing the resistance elements also negates the heat energy which the resistance would have generated.

2. At the same machining speed, the zero-resistance spark circuit reduces power consumption by 10 to $15 \%$ as compared to that of the resistance circuit.

3. The zero-resistance spark circuit can recycle the dissipated energy into the working energy again for WEDM usage. This increases the efficiency of discharge energy of the WEDM, thus improving machining speeds by about $0.1 \sim 0.2 \mathrm{~mm} / \mathrm{min}$.

\section{References}

[1] J. Y. Lee, "Green machine tool," Industrial Technology Research Institute, 2009.

[2] SODICK , 2010, AP250L, 2010, JIMTOF Booth Digest.

[3] S. K. Sinha, "Effects of wire lag in wire electrical discharge machining (WEDM)," International Journal of Engineering Science and Technology, vol. 2, no. 11, pp. 6622-6625, 2010.

[4] W. J. Hsue, Y. S. Liao, and S. S. Lu, "Fundamental geometry analysis of wire electrical discharge machining in corner cutting," International Journal of Machine Tools and Manufacture, vol. 39, no. 4, pp. 651-667, 1999.

doi: $10.1016 /$ S0890-6955(98)00046-7

[5] J.P.Kruth and K.U.Leuven, "Study of white layer of surface machined by die-sinking electro-discharge machining," Annals of the CIRP, vol. 44, 1995.

[6] G. Rohit, "Effect of process parameters on performance measures of wire electrical discharge machining," Ph.D. dissertation, Mechanical Engineering Department, National Institute of Technology, HARYANA,INDIA, 2010. 
[7] M. Kunieda, "Advancements in fundamental al studies on edm gap phenomena," in The 16th International Symposium on Electromachining (ISEM-XVI), Shanghai, China, 2010, pp. 15-23.

[8] P. G. Hewitt, Conceptual physics: The high school physics program: Addison-Wesley Longman, Inc., 2001.

[9] L. Iuliano, M. G. Violante, A. Gatto, and E. Bassoli, "Study of the edm process effects on aluminium alloys," International Journal of Manufacturing Technology and Management, vol. 14, no. 3, pp. 326-341, 2008. doi: $10.1007 / \mathrm{s} 00170-006-0672-6$

[10] Y. C. Lin and H. S. Lee, "Machining characteristics of magnetic force-assisted edm," International Journal of Machine Tools and Manufacture, vol. 48, no. 11, pp. 1179-1186, 2008.

doi: 10.1016/i.ijmachtools.2008.04.004

[11] S. S. Mahapatra and A. Patnaik, "Optimization of wire electrical discharge machining (wedm) process parameters using taguchi method," The International Journal of Advanced Manufacturing Technology, vol. 34, no. 9-10, pp. 911-925, 2007. doi: 10.1504/IJMTM.2008.017731
[12] K. H. Ho and S. T. Newman, "State of the art electrical discharge machining (edm)," International Journal of Machine Tools and Manufacture, vol. 43, no. 13, pp. 1287-1300, 2003. doi: 10.1016/S0890-6955(03)00162-7

[13] G. S. Prihandana, M. Mahardika, M. Hamdi, Y. S. Wong, and K. Mitsui, "Effect of micro-powder suspension and ultrasonic vibration of dielectric fluid in micro-edm processes - taguchi approach," International Journal of Machine Tools and Manufacture, vol. 49, no. 12-13, pp. 1035-1041, 2009.

doi: 10.1016/j.ijmachtools.2009.06.014

[14] C. P. Wang and S. H. Chen, "The study of equalization of performance for wire cut edm," M.S. Thesis, Mechanical Engineering, National Chin-Yi University of Technology, Taichung, Taiwan, 2013. 